more specific discussion of these issues is provided by Professor Peter Yellowlees, a community psychiatrist who has been influential in the development of eH ealth applications in Australian psychiatry. There is obviously merit in using internet-based technology to consult with remote rural communities who lack their own specialist psychiatrist, and the theme is taken up in our third contribution, from $\mathrm{Dr}$ D onald $\mathrm{H}$ ilty and colleagues at the U niversity of C alifornia. They write from a US perspective, and discuss the difficult question of whether telepsychiatry is a cost-efficient way of delivering services. The answer appears to be 'Maybe, in some circumstances'. Finally, Dr Paul McLaren, a consultant psychiatrist from London, brings us back to Europe and cautions that, although professionals like to use videoconference facilities to organise discussions or teaching around clinical matters, there is still resistance to the use of the technology for direct clinical contact. Whether such prejudice will evapo rate as we all become more 'internet literate' is likely to vary according to culture (in every sense of that word).

\title{
eHealth and ePsychiatry for Europe
}

\author{
Ricky J. Richardson
}

Honorary Consultant Paediatrician, Great Ormond Street Hospital for Children, London; Chairman, UK eHealth Association; Chairman, EHTEL eHealth Working Group; Vice-President, International Society for Telemedicine; Clinical Director, HealthSystems Consultants Ltd, 7 Emlyn Road, London W12 9TF, UK, email r.j.richardson@BTinternet.com

\begin{abstract}
he use of the term 'eH ealth' is gathering momentum across Europe as the wider implications of the health care reforms enabled by information technology become apparent. There is a growing realisation by both health care providers and consumers alike that change in the sector is now imperative and timely. Member states of the European Community are all facing an increase in the requirement for health care provision because of changing demography, in particular ageing populations. In the face of an increasing demand for services, the existing model for health care delivery is arguably inadequate. In many ways it is economically unsustainable, even by the wealthiest countries in Europe.

To date, the use of information technology in the European health care sector has been on a pilot basis. $0 \mathrm{n}$ the other hand, we are beginning to see the widespread deployment of managed clinical networks, electronic patient records and other applications made possible by information technology. It is arguable that such applications are now challenging a traditional model of health care delivery that has remained largely unchanged for over 6000 years.

The generic term 'eH ealth' embraces four central pillars of activity. These are:

o clinical applications

O elearning tools

$O$ use of the media

o lifetime health records.
\end{abstract}

\section{Clinical applications}

The first pillar supports an array of clinical applications, which include teleconsultations. These may be arranged in a variety of ways, including interactive videoconferencing (previously known as 'telemedicine', a now obsolete term) or face-to-face consultations via video-links. 0 ther eH ealth applications include software that supports clinical decisionmaking, vital signs monitoring services managed by call centres, telephone-enabled health information (such as the nurse-led service established through N HS D irect in the UK), national eBooking and ePrescription services, home telecare and eN ursing. Few of these facilities are yet applicable to the provision of psychiatric services, but they could become relevant as the infrastructure of eH ealth grows.

\section{eLearning tools}

The second pillar is the use of eLearning to ols to deliver personalised continuing educational programmes to professionals. The traditional, hierarchical health care professional community is being replaced by a more horizontal structure, based around the multi-disciplinary team.

W ithin this evolving structure, there is a different work ethic. Patients are increasingly involved in decision-making about their own clinical management. In the future, the patient will be placed at the centre of the care pathway. In other words, gone are the days when the patient said 'Yes doctor', 'N o doctor', 'I will do what you say doctor' and was grateful for a few minutes of the doctor's valuable time. Patients are becoming informed partners in the health care exchange process: empowered patients know exactly what they want and from where they wish to obtain the service, and if they do not get what they want from one physician, they are willing to go elsew here.

\section{Use of the media}

The third pillar of eH ealth concerns the proactive use of the media - television, radio, newspapers, journals and magazines - to deliver appropriate health care messages to specific segments of the general public. Educating the public about health is no longer the province of public
We are beginning to see the widespread deployment of managed clinical networks, electronic patient records and other applications made possible by information technology. It is arguable that such applications are now challenging a traditional model of health care delivery that has remained largely unchanged for over 6000 years. 
information films. N evertheless, the aim is similar: to inform the general public, so that their demand for health care is more focused and appropriate.

\section{Lifetime health record}

The fourth pillar is perhaps the most exciting of all, namely the building of a lifetime health record for each citizen. The envisaged European model includes the issuing of an electronic record to a foetus when the mother's pregnancy is first recognised. This can then become a record of every health care event that the individual experiences over a lifetime. To this accumulating and dynamic dataset can be added genetic information, the individual's changing socioeconomic status throughout life, environmental data such as ambient temperature and pollution levels, as well as information on lifestyles.

There are, of course, major obstacles to the implementation of the lifetime health record, notably the ethical implications of such centralisation of personal data. These will need to be fully debated and controversies regarding civil rights and privacy resolved.

\section{The European future}

The challenge ahead is enormous, but eventually, once the process has started to gather momentum, the benefits for the European patient community are likely to be massive. For example, the duplication of resources that currently exists, with each member state having a pyramidal structure of health care delivery, could be rationalised.

There is an urgent need to move the health care exchange point outside the existing infrastructures (i.e. hospitals and clinics) and, where possible, to make services available within the community. If consultation by electronic media, rather than face to face, were to be widely implemented, we could look forward to a time when diagnostic assessments are carried out in the retail environment or in people's homes, where they spend most of their time, and not in hospitals or clinics. For those vulnerable citizens who have chronic diseases, and especially those who are unable or unwilling to attend hospital for follow-up appointments, it will be possible to conduct many diagnostic tests in the home. W ith the increasing number of elderly citizens in our community, there will be a need for 'sentinel' devices in homes, which will support their independence and provide a safe environment for them. Such devices could be especially relevant to those with dementing illnesses. Some countries in Europe have already begun this process. In the UK, the national programme for health care reform is under way, with a massive increase in investment by the government in the $\mathrm{N}$ ational $\mathrm{H}$ ealth Service (N HS) over the next 8-10 years. Much of the early spending will be on strengthening the information technology component of the N HS, thus making the changes alluded to above possible.

$N$ ot least of the challenges will be the need to accommodate the very disparate health care provision and outcomes in those countries that will be joining the European Community over the next few years. The health care needs of their citizens must be taken into consideration, as, when these countries become full members of the Community, they will have the right to receive health care services matching those received by citizens of the other member states. The time for pilot studies in telemedicine and eH ealth is long past. W hat is necessary now is the large-scale and widespread implementation of eH ealth programmes that will enable European citizens to benefit from quality health care services with equity across the European Community as a whole.

\section{This article is}

based on a book chapter published in Telepsychiatry and e-Mental Health (eds R. Wootton,

P. Yellowlees \&

P. McLaren). London: Royal Society of Medicine (2003). Professor Yellowlees is a director of HealthShare.

\section{Broadband telecommunications: the bricks and mortar of future eM ental health systems}

\section{Peter Yellowlees}

Professor of Psychiatry, Centre for Online Health, Level 3, GP South Building (78), Staff House Road, University of Queensland, St Lucia 4072, Australia, email P.Yellowlees@uq.edu.au

ealth care will undoubtedly change over the next 20 or 30 years as eH ealth technologies become increasingly used and accepted (Treister, 1997; Yellowlees, 1997, 2001). At a global level, the health care system is moving away from episodic care to concentrating on continuity of care, especially for patients with chronic diseases (Yack, 2000), who will give rise to the greatest disease burden in the future (Murray \& Lopez, 1999). Many countries are gradually moving away from a focus on the service provider to a focus on the informed patient, and from an individual approach to treatment to a team approach. Increasingly there is a concern less with the treatment of illness and more with the need for wellness promotion and illness prevention, which, of course, parallels a shift away from traditional care to community care.

This is the model of the 'information age health care' described by Ferguson (1994). To move to this future, there needs to be a strengthening of the availability and use 